\title{
Computer Simulation on Fuzzy Control of Semi-active Suspension System Based on the Whole Vehicle
}

\author{
Jianfeng Wang ${ }^{1}$ and Chuanxue Song ${ }^{1 *}$ \\ ${ }^{1}$ State Key Laboratory of Automotive Simulation and Control, \\ Jilin University, Changchun, Jilin, China \\ jfwang10@mails.jlu.edu.cn, songchx@126.com
}

\begin{abstract}
With the development of technology, new materials have been invented, which have been applied to improve the performance of structures. Recently, researchers pay their attention to controllable fluids and its applications. Magneto rheological (MR) damper is a kind of devices that uses rheological fluids to modify their mechanical properties. Their mechanical simplicity, large dynamic range, low power requirements, large force capacity, robustness and safe manner operation in case of failure have made them attractive devices to semi-active control in civil, aerospace and automotive fields. The characteristics of the MR damper will change when the rheological fluid is exposed to a magnetic field changing its stiffness and damping coefficients. In this paper, the mathematical models of a seven-degree-of-freedom suspension system based on the whole vehicle are established and the fuzzy controller of vehicle semi-active suspension system is designed. Using Matlab/Simulink software package, the simulation results show that the performance of MR semi-active suspension system with fuzzy controller is better than that of passive suspension system. It is a successful reference for the application of MR semi-active suspension in the vehicle.
\end{abstract}

Keywords: Computer simulation; whole vehicle; semi-active suspension; fuzzy controller

\section{Introduction}

There are mainly three types of control devices: passive devices, active devices and semiactive devices. Semi-active devices offer the versatility and the adaptability of active device, and the reliability of the passive device. They can operate with power supply (active device) and without power supply (passive device). Magneto rheological (MR) dampers, variable orifice dampers and tuned liquid dampers are examples of semi-active devices.

MR fluids can be regarded as a smart material. Varying strength of external magnetic field can change and control the rheological properties of MR fluids. A typical MR fluid contains $20-40 \%$ by volume of relatively pure, soft iron particles having a dimension of 3 to 5 microns. These particles are suspended in mineral oil, synthetic oil, water, or glycol. A variety of proprietary additives similar to those found in commercial lubricants are commonly added to discourage gravitational settling and promote particle suspension, enhance lubricity, modify viscosity, and inhibit wear [1]. In the absence of an applied field, MR fluids behave Newtonian-like fluid. However, in the presence of an applied magnetic field, the iron particles

* Corresponding author. Tel.: +18686627621; fax: +0431-86959525.

E-mail address: Songchx@126.com (Changchun,china). 
acquire a dipole moment aligned with the external field which causes the particles to form linear chains parallel to the field, as shown in Figure 1(a). This phenomenon can solidify the suspended iron particles and restrict the fluid's movement. MR fluid damper uses the properties of MR fluid to control the vibration of a system. The magnitude of force that an MR damper can deliver depends on the properties of MR fluids, their flow pattern, and the size of the damper. Figure 1(b) represents the structure of MR damper.

Recently, MR fluid dampers have been widely applied to control and suppress unwanted vibration and shock for various systems such as landing gear, helicopter lag dampers, vibration isolation systems, vehicle seat suspension systems, civil structures, military equipments, prosthetic limbs and so on. MR dampers are of key performance advantages, including continuously controllable force, rapid response, and low power consumption, which can be readily optimized in design procedures [2-3]. MR dampers can be analyzed using available models and are amenable to innovative design concepts [4-5].

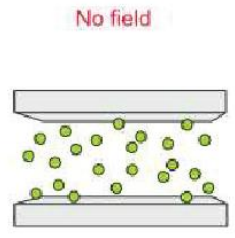

(a)

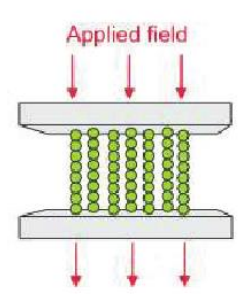

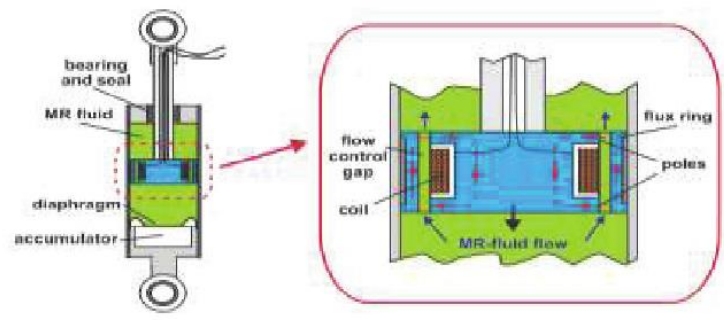

(b)

\section{Figure 1. (a) China-like structure formation in MR fluids [6-7], (b) Typical MR damper [6-7]}

In the present study, the suspension system of a passenger car is modified to reduce the amplitude of the car vibration caused by the road. In the passive suspension system, the stiffness and damping parameters are fixed and effective over a certain range of frequencies.

To solve this problem, the semi-active suspension systems are used, which have the capability of adapting themselves to the changing road conditions by using an actuator. Therefore, an MR damper is added to an ordinary suspension system while the other parts of the suspension system are intact. The significance of using the MR damper is that its viscosity changes with the magnetic field. A schematic model of the MR damper is shown in Figure 2.

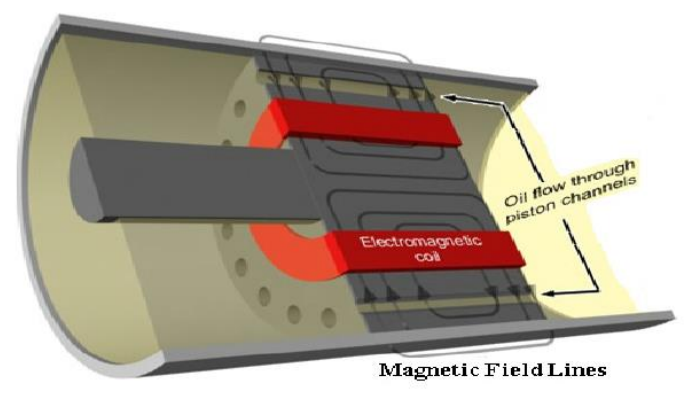

Figure 2. Schematics model of MR damper

Swevers et al., have presented a flexible and transparent model-free control structure based on physical insights in the car and semi-active suspension dynamics used to linearize and 
decouple the system, and decentralized linear feedback [8]. A load-dependent controller design approach has been presented to solve the problem of multi-objective control for vehicle active suspension systems by using linear matrix inequalities [9]. Du and Zhang have presented $\mathrm{H} \infty$ control problem for active vehicle suspension systems with actuator time delay [10]. An approach to design static output feedback and non-fragile static output feedback $\mathrm{H}_{\infty}$ controllers for active vehicle suspensions by using linear matrix inequalities and genetic algorithms have been searched [11]. Vibration control performance of a semiactive electrorheological seat suspension system using a robust sliding mode controller has been searched by Huang and Chen [12]. Ieluzzi et al. have investigated the overall performance of a semi-active suspension control for a heavy truck [13]. Spectral decomposition methods have been applied to compute accurately the rms values for the control forces, suspension strokes and tire deflection a front and rear in a half-car model with preview [14]. Guclu has presented vibration control performance of a seat suspension system of non-linear full vehicle model using fuzzy logic controller [15]. A multidisciplinary optimization method has been applied to the design of mechatronic vehicles with active suspensions [16]. Neural network control method has been developed to control a seat suspension system of non-linear full vehicle model [17]. Yildirum and Uzmay have investigated the vertical vibrations of vehicles using a neural network [18]. An active horizontal spray-boom suspension, reducing yawing and jolting, has been designed by Anthonis and Ramon [19]. A semi-active control of vehicle suspension system with magneto rheological (MR) damper has been presented by Yao et al. [20]. Spentzas and Kanarachos have presented a methodology for the design of active/hybrid car suspension systems with the goal to maximize passenger comfort [21]. A methodology for the design of active car suspension systems has been presented [22]. Yagiz and Yüksek have researched sliding mode control of active suspensions for a full vehicle model [23].

In this paper, a fuzzy control method of vehicle's vibration is proposed. The paper first describes the vehicle suspension model. And then, full consideration based on the magneto rheological damper is presented in this paper. The comparison between proposed fuzzy control system and passive control system is given and discussed. Finally, the effectiveness of the proposed control method is concluded.

\section{Vehicle Models}

Many possibilities arraying exist for describing the car suspension behavior (quarter-car model, half-car model and full-car model). Based on extensive literatures relating to these models (Croizet and Gatignol, 2002), the full-car model is presented in the following section.

The vehicle suspension system is represented as a linear seven degree-of-freedom (DOF) system. It consists of a single sprung mass (car body) connected to four unspring masses (front-left, front-right, rear-left and rear-right wheels) at each corner. The spring mass is free to bounce, pitch and roll while the unspring masses are free only to bounce vertically with respect to the sprung mass. All other motions are neglected for this model. Hence this system has seven degrees of freedom and allows simulation of tyre load forces in all four tyres, body acceleration and vertical body displacement as well as roll and pitch motion of the car body. The suspensions between the sprung mass and unsprung 
masses are modelled as linear viscous dampers and linear spring elements, while the tyres are modelled as simple linear springs without damping. For simplicity, all pitch and roll angles are assumed to be small.

The model of a full-car suspension system is shown in Figure 3. The full-vehicle suspension model is represented as a linear seven degree-of-freedom system. The lateral dynamics of the vehicle are ignored. It consists of a single sprung mass $m_{1}$ (car body) connected to four unsprung masses $m_{4} \cdots m_{7}$ (front-left, rear-left, front-right and rearright wheels) at each corner. The suspensions between the sprung mass and unsprung masses are modelled as linear viscous dampers and spring elements, while the tyres are modelled as simple linear springs without damping components (exactly in a same way as with quarter-car and half-car models). The actuator systems between the sprung body and the wheels provide forces determined by the displacement of the actuators. The dampers between the body and the wheels represent sources of conventional damping such as friction between the mechanical elements. For the vehicle modelling full-car will be used as a good approximation of the entire car.

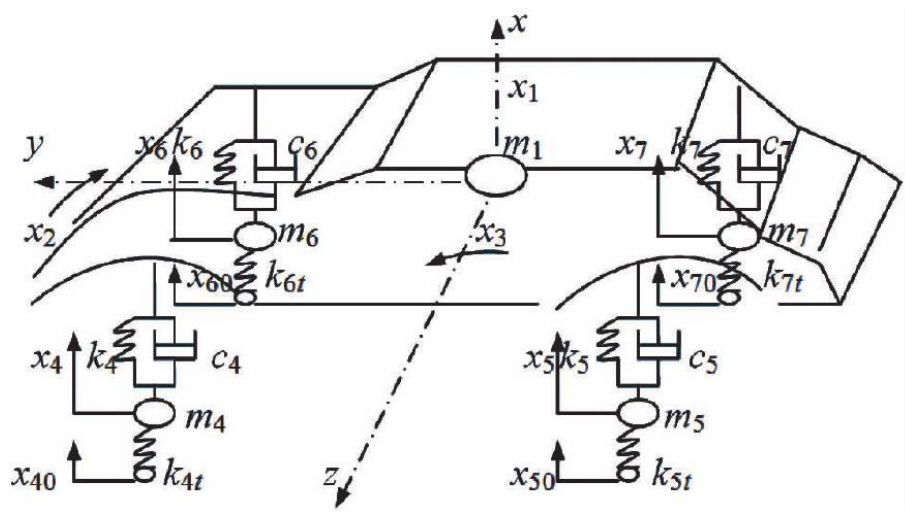

Figure 3. Full-model

Set $l_{f}$ is the distance of the front two tire center, $l_{r}$ is the distance of the rest two tire center, front axle distance of the centric distance is $a$, The rear axle distance of the centric distance is $b$. Respectively, $x_{1} 、 x_{4} 、 x_{5} 、 x_{6}$ and $x_{7}$ represent the car body, front left, rear left, front right wheel and rear right wheel vertical motion displacement, $x_{2}$ and $x_{3}$ represent the car body heeling and pitch Angle. And $m_{1}, m_{4}, m_{5}, m_{6}, m_{7}$ stands for car body, frontleft, rear-left, rear-right wheels, and $m_{2}, m_{3}$ for heeling and pitch moment of inertia of the vehicle respectively.

We establish the motion equation of passive suspension system of whole vehicle model based on the Lagrange equations, written in matrix form:

$$
M \ddot{X}+C \dot{X}+K X=K_{t} Q
$$


In Eqs.(1) :

$$
\begin{gathered}
M=\left[\begin{array}{ccccccc}
m_{1} & 0 & 0 & 0 & 0 & 0 & 0 \\
0 & m_{2} & 0 & 0 & 0 & 0 & 0 \\
0 & 0 & m_{3} & 0 & 0 & 0 & 0 \\
0 & 0 & 0 & m_{4} & 0 & 0 & 0 \\
0 & 0 & 0 & 0 & m_{5} & 0 & 0 \\
0 & 0 & 0 & 0 & 0 & m_{6} & 0 \\
0 & 0 & 0 & 0 & 0 & 0 & m_{7}
\end{array}\right] \quad K=\left[\begin{array}{llllllll}
k_{11} & k_{12} & k_{13} & k_{14} & k_{15} & k_{16} & k_{17} \\
k_{21} & k_{22} & k_{23} & k_{24} & k_{25} & k_{26} & k_{27} \\
k_{31} & k_{32} & k_{33} & k_{34} & k_{35} & k_{36} & k_{37} \\
k_{41} & k_{42} & k_{43} & k_{44} & k_{45} & k_{46} & k_{47} \\
k_{51} & k_{52} & k_{53} & k_{54} & k_{55} & k_{56} & k_{57} \\
k_{61} & k_{62} & k_{63} & k_{64} & k_{65} & k_{66} & k_{67} \\
k_{71} & k_{72} & k_{73} & k_{74} & k_{75} & k_{76} & k_{77}
\end{array}\right] \\
C=\left[\begin{array}{llllllll}
c_{11} & c_{12} & c_{13} & c_{14} & c_{15} & c_{16} & c_{17} \\
c_{21} & c_{22} & c_{23} & c_{24} & c_{25} & c_{26} & c_{27} \\
c_{31} & c_{32} & c_{33} & c_{34} & c_{35} & c_{36} & c_{37} \\
c_{41} & c_{42} & c_{43} & c_{44} & c_{45} & c_{46} & c_{47} \\
c_{51} & c_{52} & c_{53} & c_{54} & c_{55} & c_{56} & c_{57} \\
c_{61} & c_{62} & c_{63} & c_{64} & c_{65} & c_{66} & c_{67} \\
c_{71} & c_{72} & c_{73} & c_{74} & c_{75} & c_{76} & c_{77}
\end{array}\right] \\
X=\left[\begin{array}{cccccccccc}
0 & 0 & 0 & 0 \\
x_{1} & x_{2} & x_{3} & x_{4} & x_{5} & x_{6} & x_{7}
\end{array}\right]^{T} \\
K_{t}=\left[\begin{array}{cccc}
0 & 0 & 0 \\
0 & 0 & 0 & 0 \\
k_{t 1} & 0 & 0 & 0 \\
0 & k_{t 2} & 0 & 0 \\
0 & 0 & k_{t 3} & 0 \\
0 & 0 & 0 & k_{t 4}
\end{array}\right]
\end{gathered}
$$

Part elements of the matrice $K$ are shown in the table below:

\begin{tabular}{|c|c|c|c|c|c|}
\hline $\begin{array}{c}\text { The } \\
\text { serial } \\
\text { number }\end{array}$ & Element & Expression & $\begin{array}{c}\text { The } \\
\text { serial } \\
\text { number }\end{array}$ & Element & Expression \\
\hline 1 & $k_{11}$ & $k_{4}+k_{5}+k_{6}+k_{7}$ & 12 & $k_{25}$ & $-l_{f} k_{5}$ \\
\hline 2 & $k_{12}$ & $l_{f}\left(k_{4}-k_{6}\right)+l_{r}\left(k_{5}-k_{7}\right)$ & 13 & $k_{26}$ & $l_{f} k_{6}$ \\
\hline 3 & $k_{13}$ & $-a\left(k_{4}+k_{6}\right)+b\left(k_{5}+k_{7}\right)$ & 14 & $k_{27}$ & $l_{r} k_{7}$ \\
\hline 4 & $k_{14}$ & $-k_{4}$ & 15 & $k_{31}$ & $k_{13}$ \\
\hline 5 & $k_{15}$ & $-k_{5}$ & 16 & $k_{32}$ & $k_{23}$ \\
\hline 6 & $k_{16}$ & $-k_{6}$ & 17 & $k_{33}$ & $a^{2}\left(k_{4}+k_{6}\right)+$ \\
\hline 7 & $k_{17}$ & $-k_{7}$ & 18 & $k_{34}$ & $a k_{4}$ \\
\hline 8 & $k_{21}$ & $k_{12}$ & 19 & $k_{35}$ & $-b k_{5}$ \\
\hline 9 & $k_{22}$ & $l_{f}^{2}\left(k_{4}+k_{6}\right)+l_{r}^{2}\left(k_{5}+k_{7}\right)$ & 20 & $k_{36}$ & $a k_{6}$ \\
\hline 10 & $k_{23}$ & $-a l_{f}\left(k_{4}-k_{6}\right)+b l_{r}\left(k_{5}-k_{7}\right)$ & 21 & $k_{37}$ & $-b k_{7}$ \\
\hline 11 & $k_{24}$ & $-l_{f} k_{4}$ & & \\
\hline
\end{tabular}




$$
\begin{aligned}
& \text { And } k_{41}=k_{14}, k_{42}=k_{24}, k_{43}=k_{34}, k_{44}=k_{4}+k_{4 t}, k_{45}=k_{46}=k_{47}=0 \\
& k_{51}=k_{15}, k_{52}=k_{25}, k_{53}=k_{35}, k_{55}=k_{5}+k_{5 t}, k_{54}=k_{56}=k_{57}=0 \\
& k_{61}=k_{16}, k_{62}=k_{26}, k_{63}=k_{36}, k_{66}=k_{6}+k_{6 t}, k_{64}=k_{65}=k_{67}=0 \\
& k_{71}=k_{17}, k_{72}=k_{27}, k_{73}=k_{37}, k_{77}=k_{7}+k_{7 t}, k_{74}=k_{75}=k_{76}=0
\end{aligned}
$$

The matrix $C$ expression form as the same as the matrix $K$, the semi-active suspension control system is on the basis of the passive suspension system with a controllable damping force $U$, which is produced by Control magneto rheological damper. Therefore, the four wheels are equipped with a shock absorber, which has four control forces. The semi-active suspension control system of the whole vehicle model equation is:

$$
\ddot{M}+C \dot{X}+K X=B \bar{U}+K_{t} Q
$$

Where $\bar{U}=\left[\begin{array}{llll}u_{1} & u_{2} & u_{3} & u_{4}\end{array}\right]$, Which is Controllable damping force matrix, and $B$ is damping force coefficient matrix, it can be expressed as:

$$
B=\left[\begin{array}{ccccccc}
1 & l_{f} & -a & -1 & 0 & 0 & 0 \\
1 & l_{r} & -b & 0 & -1 & 0 & 0 \\
1 & -l_{f} & -a & 0 & 0 & -1 & 0 \\
1 & -l_{r} & -b & 0 & 0 & 0 & -1
\end{array}\right]^{T}
$$

\section{The Design of Fuzzy Controller}

\subsection{The controller design}

Fuzzy controller is based on fuzzy control rules based on conditional statements describing language, its control rules by human experience, generally has two input variables, output variables chosen as $U$.

The fuzzy control of semi-active suspension system is based on the suspension system relative displacement $\left(x_{2}-x_{1}\right)$ of non-sprung mass and sprung mass and its change rate $\left(\dot{x}_{2}-\dot{x}_{1}\right)$ as inputs, which will be recorded as $e, e c$; magneto rheological damper semiactive suspension with MR damper with adjustable damping force $u$ as the output of fuzzy controller, the control system is shown in Figure 4: 


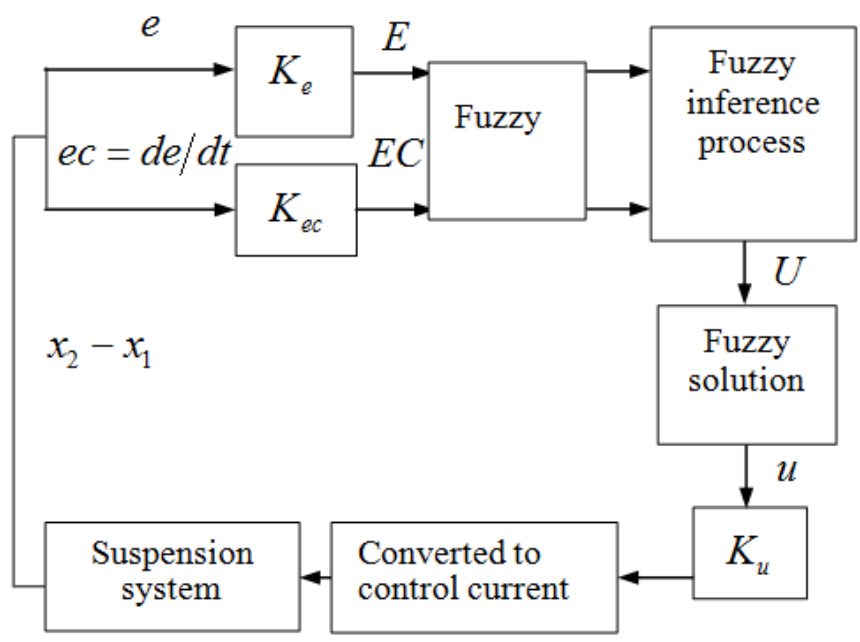

Figure 4. Fuzzy control system structure

\subsection{The fuzzy control rules}

Fuzzy control rules are generally represented as a set of fuzzy conditional statement, such statement is used to describe the input and output state variable is a collection of words referred to as fuzzy state variables. Often use words such as "large, medium and small" to describe the input and output variables.

The common fuzzy conditional statement has: if $A$ then $B$ or if $A$ and $B$ then $C$.Two input fuzzy controller [NB (negative big), NM (negative medium), NS (negative small), ZE (zero), PS (positive small), PM (positive medium), PB (positive big)] 7 language fuzzy set to capture the above, the formation of the 49 control rules. Design the fuzzy rule base is shown in Table 1. And when $E$ and $E C$ is equal to 0 , maintaining the status quo; when $E$ is not self-correcting, $U$ is not 0 , and depends on the size and direction of $E$ and $E C$. Fuzzy Control adopt "Mamdani" method, the reasoning is the "max-min" method.

Table 1. Fuzzy control rule

\begin{tabular}{|c|c|c|c|c|c|c|c|c|}
\hline & \multirow{2}{*}{ J } & \multicolumn{7}{|c|}{ E } \\
\hline & & PB & PM & PS & ZE & NS & NM & NB \\
\hline \multirow{7}{*}{ EC } & NB & $\mathrm{PM}$ & PS & $\mathrm{ZE}$ & NS & NS & NS & NM \\
\hline & $\mathrm{NM}$ & PM & $\mathrm{PM}$ & PS & NS & $\mathrm{NM}$ & NM & $\mathrm{NM}$ \\
\hline & NS & PB & PB & PM & NS & NM & $\mathrm{NM}$ & NB \\
\hline & ZE & PB & PB & PM & ZE & $\mathrm{NM}$ & NB & NB \\
\hline & PS & PB & PM & PM & PS & $\mathrm{NM}$ & NB & NB \\
\hline & PM & PM & PM & PM & PS & NS & $\mathrm{NM}$ & $\mathrm{NM}$ \\
\hline & PB & PM & PS & PS & PS & $\mathrm{ZE}$ & NS & $\mathrm{NM}$ \\
\hline
\end{tabular}




\subsection{Scale factor and the Membership Function}

Fuzzy before the variable standardization, process standardization is the domain of real variables, $e, e c$ and $u$ and the standardized variables after $E, E C$ and $U$ have the following relationship:

$$
E=e / k_{e}, E C=e c / k_{e c}, U=u / k_{u}
$$

In Eqs. (3) $k_{e}, k_{e c}$ and $k_{u}$ is the scale factor normalized by the controller output range by the suspension system and the corresponding membership function domain of decision. Generally speaking, $k_{e}, k_{e c}$ value greatly of the corresponding language electrically, and vice versa. The larger $k_{e}$ is, the smaller the dead zone will be. Rate of rise, which is too large a system, will be prone to large ultra-withered or even oscillation. When $k_{e c}$ is larger, it is unresponsive, and vice versa fast, but too small system is also easy to overshoot. $k_{u}$ is equivalent to the proportional gain, usually $k_{u}$ to increase, rising faster, but too large system prone to large overshoot. Membership function of the universe is divided in accordance with the physical meaning of the semi-active suspension system, variable universe fuzzy controller input incentive to produce the maximum response is determined according to the vehicle road.

Commonly used membership functions with triangular membership function, which will be bell-shaped Gaussian type membership function and membership function, etc. This triangular membership function is chosen as the membership function of input and output variables, as shown in Figure 5:

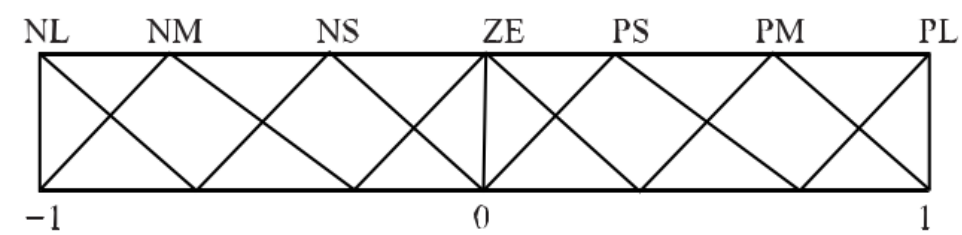

Figure 5. Membership function curve of the input and output variables

\section{The Results of Numerical Simulation}

Based on the suspension system of the vehicle model contains the front left, front right, rear left and rear right magneto rheological damper. To control the suspension system we control these four shock absorbers. For simplicity here, this paper only considers reducing body vibration acceleration and adopting four fuzzy controller to control the shock absorber, the input signal to the body is $\left(m_{1}\right)$,which with respect to the relative displacement of the four tire $\left(m_{4}, m_{5} 、 m_{6} 、 m_{7}\right)$ signal and the relative velocity signal; controlled by the fuzzy controller magneto rheological Less Vibrator current, resulting in four adjustable damping force $\left(u_{1}, u_{2} 、 u_{3} 、 u_{4}\right)$,.Generating a matrix $\bar{U}$ which is transmitted to the suspension 
system, in order to reduce body vibration activity acceleration and control the suspension system.

The parameter of the vehicle suspension system is shown in Table 2. According to eqs, (2) the establishment of the suspension system model in Matlab / Simulink environment for simulation, and compared with the passive suspension system based on magneto-rheological damper. According to the fuzzy controller design above four fuzzy controller with two inputs and one output, the front left and front right shock absorber fuzzy controller input domain of $[-0.04,0.04][-300,300]$ and $[-0.5,0.5]$, the output domain of the two inputs of the fuzzy controller is the domain of the rear left and rear right shock absorber [-0.04, 0.04] and [-1, 1], the output domain is $[-400,400]$. Using triangular membership function, fuzzy control rules is shown in Figure 5.

\section{Table 2. The basic parameters of the vehicle suspension system}

\begin{tabular}{|c|c|c|c|}
\hline Parameter & Description & Value & Unit \\
\hline$m_{1}$ & Car body mass & 876 & $K g$ \\
\hline$m_{2}$ & $\begin{array}{l}\text { Car body tilting } \\
\text { moment of inertia }\end{array}$ & 438 & $\mathrm{Kg} / \mathrm{m}^{2}$ \\
\hline$m_{3}$ & $\begin{array}{l}\text { Body pitch } \\
\text { moment of inertia }\end{array}$ & 2337 & $\mathrm{Kg} / \mathrm{m}^{2}$ \\
\hline$m_{4}, m_{6}$ & Front tire mass & 153 & $K g$ \\
\hline$m_{5}, m_{7}$ & Rear tire mass & 85 & $K g$ \\
\hline$a$ & $\begin{array}{c}\text { Front track centroid } \\
\text { distance }\end{array}$ & 0.945 & $m$ \\
\hline$b$ & $\begin{array}{c}\text { Rear track centroid } \\
\text { distance }\end{array}$ & 1.718 & $m$ \\
\hline$l_{f}$ & Front distance & 1.512 & $m$ \\
\hline$l_{r}$ & Rear distance & 1.47 & $m$ \\
\hline$k_{4}, k_{6}$ & Front main stiffness & 12480 & $N / m$ \\
\hline$k_{5}, k_{7}$ & Rear main stiffness & 15730 & $N / m$ \\
\hline $\begin{array}{l}k_{4 t}, k_{5 t} \\
k_{6 t}, k_{7 t}\end{array}$ & Tire stiffness & 240 & $k N / m$ \\
\hline$c_{4}, c_{6}$ & Front main damping & 348 & $N s / m$ \\
\hline$c_{5}, c_{7}$ & Rear main damping & 782 & $N s / m$ \\
\hline
\end{tabular}

Considering the type of the road situation, assume here that the front and rear wheels through the road surface excitation of equal amplitude, but there is a certain phase difference before and after. The simulation assumes that the road surface the amplitude of excitation are $0.02 \mathrm{~m}$, frequency of $(\omega=13 \mathrm{rad} / \mathrm{s}$, the front and rear retardation $(a+b) / v=1.73$ (the set vehicle speed $v=20$ ), obtained in Figure 6, Figure 7 and Figure 8 (Curve 1 is representative of the passive suspension system, the curve 2 represents the fuzzy control of semi-active suspension system). 
International Journal of Multimedia and Ubiquitous Engineering Vol.8, No.6, (2013)

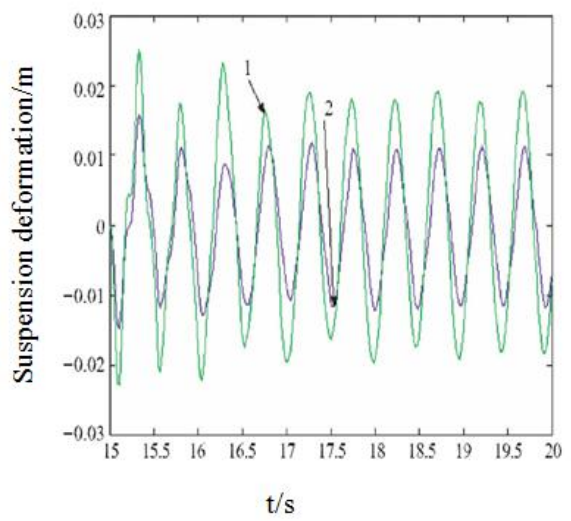

(a)Front left suspension

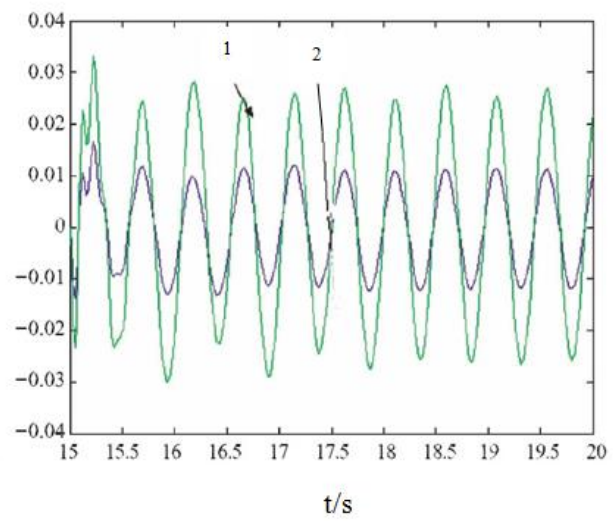

(b)Right rear suspension

Figure 6. Comparison of Suspension deformation amount

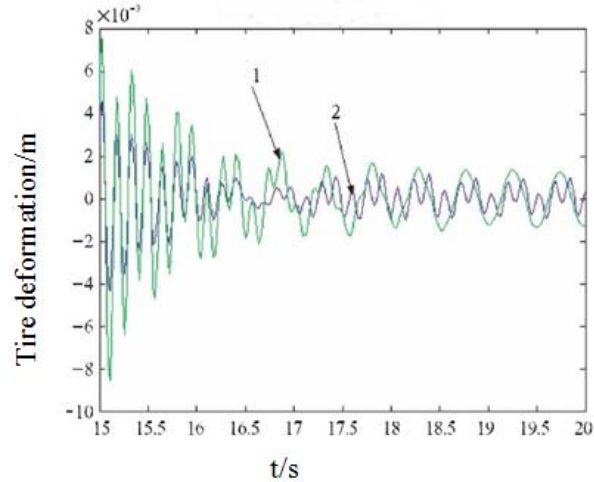

(a)Front left tire

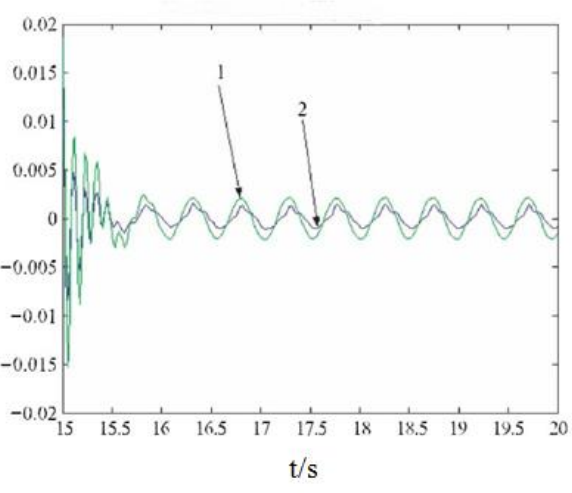

(b) Right rear tire

Figure 7. Comparison of tire deformation

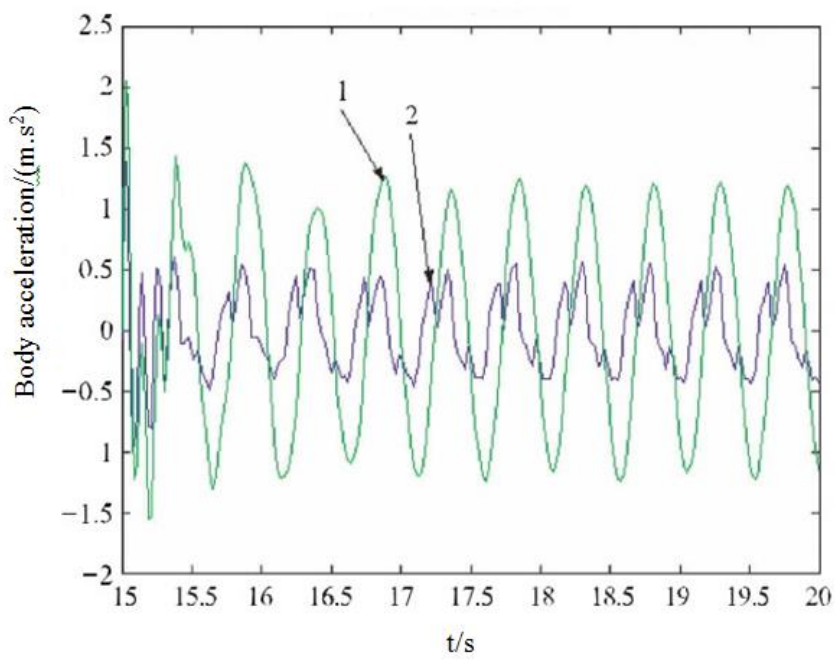

Figure 8. Comparison of body acceleration 


\section{Conclusion}

Compared to both left front suspension and rear suspension, the fuzzy control semi-active suspension system of suspension distortion is less than passive suspension system, and the change is quite gentle, fuzzy control semi-active suspension system of the tire deformation is smaller than the passive suspension system, but relatively speaking, front left tire deformation changes relative to some. Based on fuzzy control rule of semi active control suspension system can reduce the body's vibration acceleration, improve the vehicle comfort, and reaches the expected design purpose.

Simulation results show that the fuzzy controller magneto rheological semi-active suspension system can reduce the body acceleration, improve vehicle comfort and ride comfort, while reducing the amount of tire deformation and suspension.

The amount of deformation and each index change is relatively smooth, helping to improve the life of the suspension system, and allow changing the structure of the system parameters within a certain range at the same time, with considerable robustness. The results show that the control scheme is correct to provide a reference for the magneto-rheological suspension in automotive applications.

\section{Acknowledgements}

This work was supported by the National Natural Youth Science Foundation of China (51205155). The authors are grateful to the reviewers for their helpful comments and valuable suggestions during the revision of this paper.

\section{References}

[1] G. Yang, "Large-Scale Magneto rheological Fluid Damper for Vibration Mitigation: Modeling, Testing and Control", PhD Dissertation, University of Notre Dame, Indiana, (2001).

[2] Q. H. Nguyen, Y. M. Han, S. B. Choi, Y. T. Choi and N. M. Wereley, "Geometry Optimization of MR Valves Constrained in a Specific Volume Using the Finite Element Method", Smart Mater. Struct, vol. 16, no. 6, (2007), pp. 2242-2252.

[3] Q. H. Nguyen and S. B. Choi, "Optimal Design of a Vehicle Magneto rheological Damper Considering the Damping Force and Dynamic Range”, Smart Mater. Struct., vol. 18, no. 1, (2009), pp. 015013.

[4] E. Cook, W. Hu and N. M. Wereley, "Magneto rheological Bypass Damper Exploiting Flow Through a Porous Channel", J. Intell. Mater. Syst. Struct., vol. 18, no. 12, (2007), pp. 1197-1203.

[5] G. H. Hitchcock, X. Wang and F. Gordaninejad, "A New Bypass Magneto rheological Fluid Damper", ASME J. Vibr. Acoust., vol. 129, no. 5, (2007), pp. 641-647.

[6] M. T. Avraam, "MR-fluid brake design and its application to a portable muscular rehabilitation device", $\mathrm{PhD}$ Thesis, Univ.Libre de Bruxelles, Brussels, Belgium, (2009).

[7] J. D. Carlson, "Semi-active vibration suppression", In CISM Course: Semi-Active Vibration Suppression-the Best from Active and Passive Technologies, Udine, (2007) October.

[8] J. Swevers, C. Lauwerys, B. Vandersmissen, M. Maes, K. Reybrouck and P. Sas, "A model-free control structure for the on-line tuning of the semi-active suspension of a passenger car", Mechanical Systems and Signal Processing, vol. 21, (2007), pp. 1422-1436.

[9] H. Gao, J. Lam and C. Wang, "Multi-objective control of vehicle active suspension systems via loaddependent controllers", Journal of Sound and Vibration, vol. 290, (2006), pp. 654-675.

[10] H. Du and N. Zhang, "H1 control of active vehicle suspensions with actuator time delay", Journal of Sound and Vibration, vol. 301, (2007), pp. 236-252.

[11] H. Du, J. Lam and K. Y. Sze, "Non-fragile output feedback H1 vehicle suspension control using genetic algorithm", Engineering Applications of Artificial Intelligence, vol. 16, (2003), pp. 667-680.

[12] S. J. Huang and H. Y. Chen, "Adaptive sliding controller with self-tuning fuzzy compensation for vehicle suspension control”, Mechatronics, vol. 16, (2006), pp. 607-622.

[13] M. Ieluzzi, P. Turco and M. Montiglio, "Development of a heavy truck semi-active suspension control", Control Engineering Practice, vol. 14, (2006), pp. 305-312. 
[14] A. G. Thompson and B. R. Davis, "Computation of the rms state variables and control forces in a half-car model with preview active suspension using spectral decomposition methods", Journal of Sound and Vibration, vol. 285, (2010), pp. 571-583.

[15] R. Guclu, "Fuzzy logic control of seat vibrations of a non-linear full vehicle model", Nonlinear Dynamics, vol. 40, (2011), pp. 21-34.

[16] Y. He and J. McPhee, "Multidisciplinary design optimization of mechatronic vehicles with active suspensions", Journal of Sound and Vibration, vol. 283, (2011), pp. 217-241.

[17] R. Guclu and K. Gulez, "Neural network control of seat vibrations of a non-linear full vehicle model using PMSM", Mathematical and Computer Modeling, vol. 47, (2011), pp. 1356-1371.

[18] S. Yildirim and I. Uzmay, "Neural network applications to vehicle's vibration analysis", Mechanism and Machine Theory, vol. 38, (2012), pp. 27-41.

[19] J. Anthonis and H. Ramon, "Design of an active suspension to suppress the horizontal vibrations of a spray boom", Journal of Sound and Vibration, vol. 266, (2012), pp. 573-583.

[20] G. Z. Yao, F. F. Yap, G. Chen, W. H. Li and S. H. Yeo, "MR damper and its application for semi-active control of vehicle suspension system", Mechatronics, vol. 12, (2012), pp. 963-973.

[21] K. Spentzas and S. A. Kanarachos, "Design of a non-linear hybrid car suspension system using neural networks", Mathematics and Computers in Simulation, vol. 60, (2012), pp. 369-378.

[22] F. J. Amato and D. E. Viassolo, "Fuzzy Control for Active Suspensions", Mechatronics, vol. 10, (2011), pp. 897-920.

[23] N. Yagiz and I. Yüksek, "Sliding mode control of active suspensions for a full vehicle model", International Journal of Vehicle Design, vol. 26, (2012), pp. 264-276. 